\title{
Clinical assessment to the dental treatment of bruxism: literature review
}

\author{
Yu-Sung Choi* \\ Department of Prosthodontics, College of Dentistry, Dankook University, Cheonana, Republic of Korea
}

\begin{abstract}
Bruxism is a much-discussed clinical issue in dentistry. Although bruxism is not a life-threatening disorder, it can influence the quality of human life, especially through dental problems, such as, frequent fractures of dental restorations and pain in the orofacial region. This research has a goal to investigate the diagnostic methods of bruxism, to provide an appropriate information about various treatment in clinical situation, and to evaluate the effect and the usefulness of those methods. There is no certain remedy for bruxism that is a technically efficient and definitely reliable diagnosis and treatment. So, the primary purpose is to prevent the oral and maxilofacial tissue injuries from bruxism and to relieve the pain and symptom. Therefore, Combining various reversible treatments together, such as behavior modification, Oral appliances therapy and physiotherapy, is recommended. For a bruxism treatment in dental field, more researches about the factors influencing on diagnosis and cure are necessary. (J Dent Rehabil Appl Sci 2014;30(1):36-44)
\end{abstract}

Key words: bruxism; clenching; clinical assessment; diagnosis; treatment

\begin{abstract}
서론
이갈이는 비기능적인 턱 운동으로 인식되며, 비정상적 인 치아 마모, 치주 질환 및 temporomandibular disorder (TMD)를 발병시키거나 가속화 시키는 중요한 병인학적 요소로 정의된다. ${ }^{1,2}$ 이갈이의 유병률, 병인, 효과 및 관 리에 관한 많은 연구가 있었으나, 치과 진료에 적용시킬 만한 가이드라인이나 공동 합의가 아직 없다. ${ }^{1-3}$ 이갈이 가 구강 구조와 근육계에 파괴적인 영향을 미칠 것은 자 명하나, 임상적으로 정확한 상태 및 활동을 파악하는 것 은 어렵다. 따라서, 대부분의 치과의사들이 환자들이 실 제로 활동적인 이갈이를 가지고 있는지 파악하는데 어려 움이 있다. 치아 마모의 몇몇 패턴들은 이갈이의 증상으 로 생각되나, 그러한 패턴에 관해서 객관적이고 믿을만 한 평가가 임상적 진단에 필요하다. 이갈이는 다양한 측
\end{abstract}

*Correspondence to: Yu-Sung Choi, PhD

Department of Prosthodontics, College of Dentistry, Dankook University 119 Dandae-ro, Dongnam-gu, Cheonan, 330-714, Republic of Korea Tel: +82-41-550-1979, Fax: +82-41-550-1859, E-mail: yu0324@hanmail.net Received: January 3, 2014/Last Revision: March 1, 2014/Accepted: March 10, 2014
면에서 진단되어야 한다. 구강 병력에 관한 설문지, 이갈 이의 임상적 신호에 관한 구외, 구내 검사, 그리고 저작근 의 활동을 기록하는 electromyographic (EMG)이나 수면 패턴을 기록하는 polysomnographic (PSG)를 이용하는 방법 등이 있는데 이러한 진단방법들은 하나만 독립적으 로 사용되어서는 안된다. ${ }^{4.5}$ 왜냐하면 환자들은 이갈이의 존재를 깨닫지 못할 수 있고, 이갈이의 임상적 신호는 현 재의 것보다는 과거의 문제를 반영할 수 있으며, EMG와 $\mathrm{PSG}$ 는 시간에 따른 변동적인 장애만을 무작위로 나타내 기 때문이다. 교모(기계적 마모, 이상기능, 치아의 접촉 제한), 저작근 비대, 임플란트나 수복물의 실패/파절, 두 통과 저작시스템의 동통(TMD pain) 과 같은 치과문제들 은 이갈이에서 기인한다. 이갈이의 치료는 이와 같은 결 과들 중 하나를 야기하는 장애가 발생할 때 필요하다. 불 행히도 이갈이의 명확한 치료방법이 아직까지 없기 때문

Copyright@ 2014 The Korean Academy of Stomatognathic Function and Occlusion. (c) It is identical to Creative Commons Non-Commercial License. 
에 일차적인 치료 목표는 이갈이로 인한 구강 악안면 조 직의 손상을 막고 통증이나 관련 증상을 치료하는 데 있 다고 보고된다. ${ }^{6,7}$ 본 문헌고찰에서는 이갈이에 대한 진 단법을 알아보고 임상적 상황에서 가능한 다양한 치료 방법에 관한 정보를 인지하고, 그 방법들의 효과와 유용 성에 대해 알아보고자 하였다.

\section{문헌 고찰}

\section{1. 정의 (Definition)}

이갈이(Bruxism)란 저작근의 수축으로 발생하는 이 상기능의 하나로, 이악물기와 이갈기를 포함한 주행 성 또는 야행성의 비기능적 운동이라고 정의된다. ${ }^{8}$ The glossary of prosthdontics terms에서는 하악에서 저작 운동 이외의 것으로 교합외상을 초래할 수 있는 비자발 적인 규칙적이거나 불규칙적인 이상 기능으로 가는 운 동(gnashing, grinding) 또는 이 악물기(clenching)로 구 성된 구강 습관이라고 보고된다. ${ }^{9}$

\section{2. 유형 (Types)}

이갈이는 낮동안 발생하는 이악물기와 야간에 발생하 는 수면 이갈이로 나눌 수 있다. ${ }^{10}$ 이 두가지 상태는 다 른 상황에서 벌어지기 때문에 구분되어야 한다. 주로 이 악물기인 낮이갈이는 후천적 행동이라고 본다. ${ }^{10,11}$ 수면 이갈이는 phasic 형태로 발생하고 낮이갈이는 tonic 상 태의 근전도 기전을 보인다고 보고된다(Fig. 1). ${ }^{12}$ Phasic 형태는 0.25 초에서 2 초 사이에 3 번 이상의 근수축이 발 생하는 양상을 띄고 tonic 상태는 한번에 2초 이상 지속 된다. Mixed 형태는 이 둘을 합친 것으로 30 초 인터벌로 진행된다.

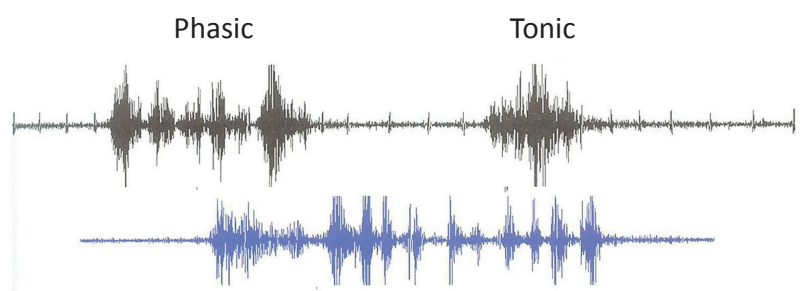

Mixed

Fig. 1. Types of bruxism.

\section{3. 유병률(Epidemiology)}

몇몇 문헌에 따르면, 이갈이 유병률은 $6-95 \%$ 로 보고 된다. ${ }^{1,13}$ 이 광범위한 발생률은 이갈이, 샘플 수 및 다른 요소의 기준을 포함하는 방법들이 다르기 때문이다. 일 반적으로, 깨어있는 시간동안 이 악물기를 한다고 스스 로 평가하는 것에 기초한 유병률은 $20 \%$ 이나 수면 시간 의 이악물기는 $10 \%$, 수면 시간의 이갈기는 $8-16 \%$ 이라 고 보고된다. ${ }^{14,15}$ Gavish는 TMJ질환을 갖고있는 청소년 기 여자아이에서 구강 습관과의 관련성을 알아보았는데 이갈이가 낮이갈이 $22 \%$, 수면이갈이 $12.7 \%$ 로 각각 높 은 유병률을 보임을 보고하였다. ${ }^{16}$ 이갈이의 발생률에서 성별에 따른 유의차는 없었고, 어릴 때 이갈이가 있는 경우 성인이 되어서 없어지는 경우는 $15 \%$ 정도로 드물 다고 보고된다. ${ }^{14}$ 그러나 또 다른 연구에서는 이갈이는 나이가 들면서 감소되며 유년기에 흔히 발생하지만 성 인까지 계속되지 않는다고 보고되어 아직 나이에 따른 유병률은 명확하지 않다고 볼 수 있다. ${ }^{17}$

\section{4. 저작계 (masticatory system)에 미치는 영향}

이갈이가 저작계에 미치는 영향은 Table 1과 같다. ${ }^{18}$

\section{5. 특성 (Characteristics)}

이갈이의 기간에 대해서 이악물기가 1 회당 20 - 40초 간 지속한다고 하였고, 또 다른 연구에서는 이갈이는 한 번에 평균 9초, 또 평균 이갈이 시간은 시간당 40 초 정도 임을 보고하였다. ${ }^{19,20} \mathrm{Clark}$ 등은 이갈이는 전체 수면시

Table 1. Effects on the masticatory system

Tooth wear (attrition)

Abfraction

Pulp \& periradicular alterations; pilpitis, pulp necrosis Alteration in crown \& root structural integrity; tooth restoration fracture

Trauma from occlusion on the periodontium; tooth mobility

Teeth hypersensitivity

Masseter muscle hypertrophy

Muscular pain, headache

Temporomandibular joint dysfuction 
간 중 평균 약 5 회 정도 나타나며, 1 회당 평균 8 초였다고 하였다. ${ }^{21}$ 이갈이의 강도에 대해서는 보고가 적은 편이 나 Clark 등은 평균이갈이 강도는 잠들기 전 최대 이악 물기의 $60 \%$ 정도임을 보고하였다. ${ }^{21}$ 최대로 이악물기가 나타날 때의 힘이 저작이나 기타 이상 기능시에 통상 허 용되는 정상적인 힘을 초과하기 때문에 이러한 힘은 대 단히 큰 양이다.

\section{6. 원인 (Etiology)}

정상적인 기능 활동의 경우 저작계가 어떤 구조물 의 손상을 최소한으로 줄이면서 필요한 기능을 수행할 수 있도록 근신경계의 반사가 조절되면서 이루어진다 면, 이갈이와 같이 이상 기능시에는 저작계를 보호할 수 있는 보호반사가 없이 발생하는 것이라고 보고되고 있 다. ${ }^{22}$ 정확한 원인은 밝혀지지 않았지만 정신적인 스트 레스, 고르지 못한 치아의 배열, 중추신경장애, 알레르 기, 유전요인, 호르몬의 변화, 약물의 복용 등 여러 요인 들이 제기되어 왔다. 스트레스가 증가하는 경우 이갈이 가 증가한다는 보고가 있으며, 외상이나 뇌출혈 등에 의 해 중추 신경계(뇌손상)가 손상받는 경우 과도한 이갈이 를 하는 경우가 있으나 한가지의 소인보다는 여러가지 원인들이 복합적으로 작용하는 것으로 보고 있다. ${ }^{22,23}$ 수 면 이갈이를 발생시키는 원인과 신경학적 매커니즘은 잘 알려지지 않고 있다. 많은 증거들이 중추 신경계에서 유도되며, 부분적으로 수면중의 각성 반응 증상과 관련 이 있다고 말하고 있다. 몇몇 연구는 교합 접촉 관계의 변화와 증가하는 수직 교합 고경과 같은 말초 구강 수용 기의 입력 피드백의 변화는 일시적으로 감소하나 이갈 이를 중단시키지는 않는다고 보고된다. ${ }^{22-25}$

\section{7. 진단(Diagnosis)}

처음 이갈이 환자를 진단할 때 우선 체크할 사항은 이 갈이나 이악물기의 활성도, 심한 정도, 발생시간 및 기 간 등을 평가하여 치료 필요 여부를 결정해야 한다. ${ }^{1,26}$ 우선 임상적인 진단을 시행한다. 설문지나 인터뷰를 통 하여 환자의 말을 듣고 구강검사나 모델 및 사진을 통해 치아와 구강조직을 검사한다.

\section{1) 임상적 진단}

설문지는 연구와 임상적 상황에서 일반적으로 흔히
Table 2. Clinical symptoms and signs of bruxism

Symptoms; questionnaires, personal interview

- Tooth-grinding sounds (by bed partners, by oneself)

- Jaw pain, toothache, headache or jaw lock in the morning

Signs; mouth, model, or photographic examination

- Tooth wear, fractures, tooth mobility, pulp necrosis, traumatic ulcers, masticatory muscle hypertrophy, buccal mucosa ridging or linea alba, tongue edge indentation

사용된다. ${ }^{1,3,26}$ 이 방법의 이점은 이갈이 정보는 주관적 일지라도 많은 인구에 적용 가능하다는 것이다. 이갈이 환자를 알아보는 설문지의 내용으로는 밤에 당신이 이 를 가는 소리를 들은 사람이 있습니까? 아침에 일어났 을 때 턱이 피로하거나 아픕니까? 치아나 치은이 아픕니 까? 일시적인 두통을 경험한 적이 있습니까? 주간에 이 갈이를 인식한 적이 있습니까? 이악물기를 인식한 적이 있습니까? 등이 있다. 설문지로 조사한 내용과 더불어 치아와 구강조직 검사를 통해 이갈이를 진단하는데 활 용한다(Table 2). 임상 검사시에 심한경우 교근이 비대 된 양상을 관찰할 수 있고, 보철물이 닪거나 깨진 것을 볼 수 있다. 또한 구강 내 뺨이나 혀에 치아 물림자국이 나타나는 경우도 있다. 또한 치아 교합면이 편평해지고, 측방으로 이를 갈므로써 상, 하악의 치아가 마모된 양상 을 보인다. 심한 경우 위아래 치아 모두가 마모되어 치 관 길이가 짧아져 수직고경이 감소된 경우도 보고되기 도 한다. ${ }^{27}$ 또한 2005년도에 발표된 수면이갈이 환자의 국제적 기준이 사용되기도 한다. 다음과 같은 조건에 부 합할 경우 수면 이갈이 환자로 보고 있다(Table 3$){ }^{28}$

\section{2) 진단 장치}

이갈이 평가를 위해 추가적인 장치를 이용한 진단법 이 이용되고 있다.,8 임상적 평가 이외에도 이갈이 현상 을 객관적으로 수치화하여 평가하는데 유용하다고 보고 되고 있다. ${ }^{29}$ 치아를 gray scaled computer image를 통해 관측하고 2 년 후 환자가 재내원시 치아를 재측정하여 처음과 2년 뒤의 치아 마모 정도를 그래프와 색을 통해 측정하는 방법이 있는데, 단기간에 이갈이를 평가하는 데는 조금 부적당한 단점이 있다. BiteStrip ${ }^{\circledR}$ (S.L.P. Ltd., Stommein, Germany)라고 불리는 기구는 수면 이갈이 에 대해 집에서 밤중에 검사를 가능케하며 손상이 치아 
Table 3. The criteria for the diagnosis of sleep bruxism (SB)

International classification of sleep disorders, 2005

The patient reports, or is aware of, tooth-grinding sounds or tooth clenching during sleep

One of the following is present:

- Abnormal wear of the teeth

- Jaw discomfort, fatigue, or pain and jaw lock upon awakening

- Masseter muscle hypertrophy upon voluntary forceful clenching

The jaw muscle activity is not butter explained by another current sleep disorder, medical or neurological sleep medication use, or substance use disorder

에 나타나기 이전에 이갈이를 진단하는데 도움이 될 것 이라고 보고된다. ${ }^{30}$ 이 기구는 축소형 근전도 기계로, 환 자가 잠을 자는 동안에 턱근육 활성화를 감지한다. 치 과의사는 이갈이의 빈도를 수치를 보고 확인할 수 있으 며 이는 치료계획을 선택하는데 도움을 줄 수 있다. 휴 대용 $\mathrm{EMG}$ 측정 시스템은 뇌파를 기록해 일상 생활 중 의 이갈이 현상을 측정하고, 또 최소의 비용으로 환자의 집에서 수면중의 이갈이 현상을 측정하는데 적당한 방 법이라고 보고된다. ${ }^{31}$ 휴대용 $\mathrm{EMG}$ 장치는 피실험자들 에 의해 쉽게 사용될 수 있고, 정밀하게 저작근의 활동 을 측정할 수 있는데, 예를 들어 이갈이의 수, 길이, 심도 등을 정확하게 측정할 수 있다. 수치가 $50 \mathrm{~Hz}$ 이상일 경 우 이갈이라고 보고된다. ${ }^{30,31}$ Bruxcore plate 구강 내 장 치인, Bruxcore-Bruxism-Monitoring-Device (BBMD, Bruxcore, Boston, MA, USA)는 객관적으로 수면중 이 갈이를 측정하기 위해 소개된 장치로 Bruxcore plate는 상업적으로 판매되고 있는 이갈이 활동을 표면에 존재 하는 미세점이 몇 개가 마모되었는지 측정하고, 마모의 부피 정도를 측정했다. $\mathrm{BBMD}$ 는 $0.51 \mathrm{~mm}$ 의 두꺼운 폴 리비닐 염화물 판이고, 2 개의 색으로 이루어진 4 개의 층 으로 되어 있고, 위 표면이 회색으로 된 점으로 구성되 어 있다. ${ }^{32}$ 이 장치는 플레이트를 고열로 달궈서 상악 캐 스트에 눌러 붙여서 제작한 후, 피실험자의 상악 악궁에 장착해준다. 미세점이 몇개나 없어졌는지를 측정하고, 몇개의 층이 벗겨졌는지를 통해 깊이를 측정한다. 두개 의 지표를 합쳐서 이갈이가 얼마나 이루어지고 있는지 지표를 얻을 수 있다.

\section{8. 치료 (Treatment)}

이갈이의 치료는 확실한 치료법은 없고 이갈이로 인
해 발생하는 문제점을 최소화해야 한다고 보고된다. ${ }^{3,8}$ 치료의 최선은 이갈이가 발생한 원인을 정확히 파악하 여 제거하는 것이다.

\section{1) 원인 제거}

가장 쉽게 할 수 있는 방법으로 스트레스를 줄이고 근 육을 이완시키는 훈련이다. 악물기, 손톱깨물기, 오징어 나 껌을 씹는 행위 등을 피하고 운동이나 놀이, 등산 등 의 여가활동을 통해 스트레스를 적절하게 해소하는 것 이 필요하다. 스트레스를 피하고 숙면을 취하기 위해 가 벼운 운동이나 반신욕, 음악치료 등을 통한 이완 등도 도움이 될 수 있다. 또한 평소에 위 아래 치아를 떨어지 게 하는 연습도 도움이 된다고 한다. 이갈이 환자의 스 트레칭 방법이 보고되고 있다. ${ }^{33}$ 우선 환자가 입을 최대 개구량에서 $75 \%$ 정도를 벌린다는 느낌으로 양측 교근 및 저작근이 스트레칭 되도록 한다(Fig. 2). ${ }^{33} 20$ 초정도
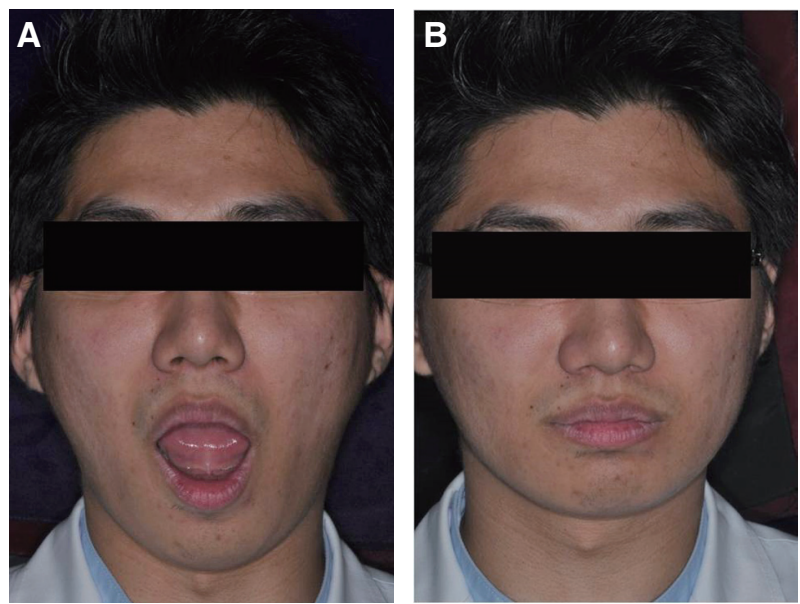

Fig. 2. Masticatory muscles stretching of bruxism. (A) Mouth opening, (B) Mouth closing. 


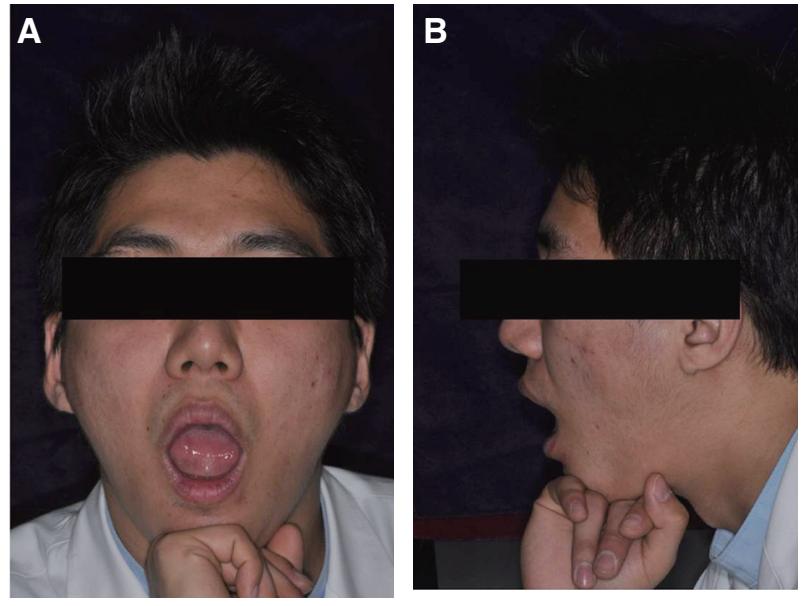

Fig. 3. Jaw opening muscles stretching of bruxism. (A) Frontal view, (B) Lateral view.

유지하고 입술이 접촉될 때까지 입을 닫고 다시 천천히 벌리고 다시 20 초를 유지한다. 이렇게 5 번 반복 시행하 면 근육이 이완되는 느낌이 들 것이라고 하였다. 또 한 가지는 개구근을 활성화시키는 운동인데 폐구근을 이완 시키므로써 근긴장을 완화시킬 수 있다고 보고된다(Fig. 3). ${ }^{33}$ 환자가 입을 크게 벌린 상태에서 하악 symphysis 하 연에 주먹을 쥔 손을 갖다 대고, 그 상태로 유지되도록 입을 계속 벌리고 주먹 쥔 손은 입을 닫는 방향으로 힘 을 주는 운동이다. 천천히 입을 다물고 이런 상태를 20 번 정도 반복하게 되면 근육이완에 도움이 된다고 한다.

\section{2) 근이완 교합 장치}

다음은 이갈이 환자로 판단되어 장치제작이 필요한 경우의 제작방법에 대하여 간단히 설명하고자 한다. 중 심위로 유도하고 캐스트를 마운팅하고 옴니백을 이용 하여 스플린트를 제작한다. 제작된 스플린트를 표시된 빨간선에 맞춰 적절하게 다듬은 후 클리어 레진을 이용 히여 전방부에 가이드될 수 있는 유도판을 형성한다. 폴 리싱하고 환자 구강 내에 장착하고 교합조정을 시행한 다. 장치의 교합조정시 유의사항이다. 중심위 상태에서 는 전치부와 구치부에서 포인트 컨택이 되어야 하고 측 방 운동시에서는 견치만 닿는 상호보호교합을 형성해주 는 것이 좋다(Fig. 4). ${ }^{34,35}$ 교합장치는 네거티브 바이오피 드백 기전을 자극시켜서 과중한 근활동을 차단하는 유 해자극을 제공하는 것으로 보고 있으며, 장치 장착시 근 활성도가 약 $50 \%$ 정도로 감소한다고 보고되어진다. ${ }^{36,37}$ 교합장치는 그 재질에 따라 soft와 hard로 나뉘는데 soft

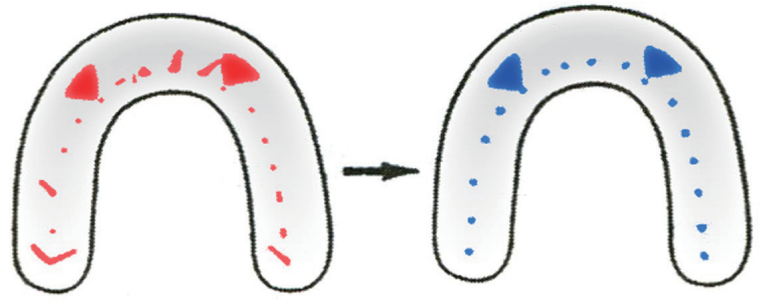

Fig. 4. Occlusal adjustment of the appliance.

의 경우 장기간 사용시 오히려 근육 활성도를 증가시 키므로 단기간 사용하여야 하며, 어린이와 뇌신경계 질 환환자에서 사용할 수 있다. 통상적으로 상악을 피개하 는 hard splint를 사용하는 것이 좋으며, 틀니의 상방에 도 사용 가능하다. 단, 수면 무호흡증 환자에서는 신중 히 사용하여야 한다. '그라인드케어(Grindcare)'라는 장 치가 이용되기도 하는데, 아이팟 크기로 관자놀이 부위 에 끈적이는 젤 패드와 함께 붙인다. 반대편 관자놀이에 는 전극이 연결되어 있다. ${ }^{4}$ 이 장비는 이를 가는 근육 움 직임이 감지될 때마다 약간의 전기 자극을 주어 관자놀 이의 긴장을 풀어 주는 것이다. 자극은 환자가 자각하지 못할 정도로 약하다. 전기 자극기를 사용한 결과 이갈이 를 하는 사람 중 절반이 3주 만에, $80 \%$ 가 6-8주 만에 이갈이를 하지 않게 되었다는 보고가 있다. ${ }^{37}$

\section{3) 보톡스 이용법}

이갈이 치료시 보톡스의 이용은 환자의 상태에 따라 그 효과에 차이가 있다. ${ }^{38}$ 보톡스 주사요법 단독으로 그 효과를 기대하기는 어려우며 교합장치를 병행하는 것 이 좋다. 보톡스 주사요법시 표층교근의 하방 $1 / 2$ 과 측 두근 전방에 자입하게 된다. 보톡스 자입량은 편측당 교 근에는 25 - 30 unit/ 3 or 5 points, 측두근에는 25 unit/5 points 정도를 주입하게 된다. 1 회 효과는 보통 6 개월 정도 로 보고되고 있고, 이후 추가적으로 반복 투여하게 된다.

\section{4) 약물 치료}

약물로 치료하는 방법도 보고되고 있는데 취침 전 소량의 삼환성 항우울제(amitriptyline or nortriptyline $20-25 \mathrm{mg}$ )를 복용시 REM수면의 감소로 인해 수면 주기가 변화되고 이갈이 활성을 감소시킬 수 있다고 보고된다. ${ }^{23} \mathrm{REM}$ 수면은 빠른 눈의 운동(rapid eyes movement)이 특징이기 때문에 앞글자를 따서 REM이 
라고 한다. 이 경우 기상시 발생하는 통증을 감소시키는 것으로 알려진다. REM 수면 앞뒤에 일어나는 뇌의 활 동이 느려지는 수면을 이에 맞춰서 Non-REM 수면이 라고 한다. 통상 Non REM 수면이 더 깊은 잠으로 알려 져 왔지만 요즘은 REM수면을 더 깊은 잠이라고 하는 학자도 있다. 그 외에 methocarbamol, L-dopa, gammahydrobutyrate, clonidine 등이 이갈이에 효과가 있는 것 으로 보고되고 있다. ${ }^{23,39}$

\section{5) 교합조정과 교정치료}

Occlusal interference가 bruxism에 영향을 미치는지 에 대하여 아직까지 여러 반대되는 의견들이 제시되어 왔다. ${ }^{8,40}$ 교합조정의 경우 비가역적인 치료이고 이갈이 치료의 목적으로 교합조정과 교정치료를 시행하는 것은 아직까지 그 정당성이 입증되지 않았으므로 주의하여야 한다.

\section{6) 보조요법}

구강 건조증이 심한 경우 이갈이로 인한 치아 마모 가 증가할 수 있으므로 저녁시간 동안 커피, 차, 콜라 등 을 피하도록 하고, 과도한 치아교모로 인하여 지각과민 이 있는 경우 국소적인 불소도포가 도움이 되며, 이때 splint를 도포용 tray로 이용 가능하다. 구강을 인공타액 이나 올리브오일 등으로 rinse하는 것, 실내에 가습하도 록 하는 것 등이 도움이 되며, 구강 건조감으로 인해 잠 에서 깨는 경우 입안을 물로 축이는 것, 타액분비 촉진 제의 복용 등이 권장될 수 있다고 보고된다. ${ }^{3,}$

\section{결론}

이갈이는 치과에서 많이 다루어지는 임상적 주제이 다. 이갈이가 삶을 위협하지는 않을 지라도, 마모나 보 철물의 파절, 악안면의 통증과 같은 치과적인 문제를 통 해 삶의 질에 영향을 미칠 수 있다. 따라서, 다양한 임 상적 방법이 수년동안 이갈이에 평가하기 위해 고안되 어 왔다. 이갈이에 대해 알아보고 임상적 상황에서 가능 한 다양한 평가 방법에 관한 정보를 제공하며 그 방법 들의 효과와 유용성에 대해 보고하고자 하였다. 진단성 과 기술적으로 효용성이 있고, 치료 결정에 영향을 미치 며 비용도 효과적인 확실한 이갈이 평가 방법은 아직 없 다. 미래의 한 방향은 임상적 검사 및 치료방법을 개선 하여 환자들에게 적용될 수 있는 프로토콜을 만드는 것
이 필요하다고 사료된다. 더 많은 임상적 연구가 이갈이 가 구강 구조, 치료 성공 및 치과 치료에 있어서 결정을 내리는 과정에 도움이 될 것으로 본다. 이갈이는 일반적 으로 치아와 치주와 근골격학적 조직의 결과로 결정되 는 임상적 문제이다. 이갈이의 보철치료에서 고정성 보 철물로 전악 수복하는 경우, 지대치의 보호와 보철물의 파절을 방지하기 위해 수면시 근기능 안정장치를 장착 하는 것이 도움이 될 수 있고, 심한 경우 보톡스 병행요 법을 이용하는 것도 추천된다. 가철성 국소의치 장착이 필요한 경우 잔존 지대치 및 잔존 치조제의 보호를 위해 conventional RPD보다는 konus denture와 같은 디자인 으로 수복하는 것도 도움이 될 수 있으며, 국소 의치의 마모를 방지하고 지대치에 위해한 힘이 가해지지 않도 록 야간장착용 의치(스플린트)를 별도로 제작하여 장착 하도록 환자에게 권장하는 것도 방법이 될 수 있다고 본 다. 또한, 이갈이는 임플란트와 그 상부 구조, 결국 임플 란트 주변의 골 소실이나 임플란트 실패를 안겨다 줄 수 도 있는 과도한 교합적 하중을 가한다. 이것에 대한 증 거는 단지 대부분 임상적 경험에 기초한 것이기는 하지 만 이갈이는 임플란트 치료에 있어 금기증이라고 볼 수 있다. 임플란트 실패를 최소화할 수 있는 실용적 제시 안이 몇몇 있다. 이갈이를 자체를 감소시키기 위한 방 법 외에도 임플란트의 수와 직경, 교합과 articulation 패 턴의 디자인, 단단한 교합 안정 장치의 최종 결과의 보 호 등을 고려해야 한다고 사료된다. 결론적으로 교모(기 계적 마모, 이상기능, 치아의 접촉제한), 저작근비대, 임 플란트나 수복물의 실패/파절, 두통과 저작시스템의 동 통(TMD pain)과 같은 치과문제들은 이갈이에서 기인 할 수 있다. 이갈이의 치료는 이같은 결과들 중 하나를 야기하는 장애가 발생할 때 필요하다. 우선 원인을 잘 파악하고, 정확한 진단을 통해 치료여부를 결정하는 것 이 중요하며, 이갈이가 심한 경우는 보철 치료 후 장치 를 제작하고 보톡스를 병행하는 요법이 가장 추천된다 고 보고되고 있다. 심한 이갈이인 경우 임플란트는 금기 증이므로 고정성 보철물이나 가철성 보철물로 제작하는 게 추천된다고 사료된다.

\section{References}

1. Koyano K, Tsukiyama Y, Ichiki R, Kuwata T. Assessment of bruxism in the clinic. J Oral Rehabil 2008;35:495-508. 
2. Svensson P, Jadidi F, Arima T, Baad-Hansen L, Sessle BJ. Relationship between craniofacial pain and bruxism. J Oral Rehabil 2008;35:524-47.

3. Lobbezoo F, van der Zaag J, van Selms MK, Hamburger HL, Naeije M. Principles for the management of bruxism. J Oral Rehabil 2008;35:509-23.

4. Jadidi F, Castrillon E, Svensson P. Effect of conditioning electrical stimuli on temporalis electromyographic activity during sleep. J Oral Rehabil 2008; 35:171-83.

5. Saletu A, Parapatics S, Saletu B, Anderer P, Prause W, Putz H, Adelbauer J, Saletu-Zyhlarz GM. On the pharmacotherapy of sleep bruxism: placebo-controlled polysomnographic and psychometric studies with clonazepam. Neuropsychobiology 2005;51: 214-25.

6. Lobbezoo F, van der Zaag J, Naeije M. Bruxism is mainly regulated centrally, not peripherally. J Oral Rehabil 2001;28:1085-91.

7. Lavigne GJ, Khoury S, Abe S, Yamaguchi T, Raphael K. Bruxism physiology and pathology: an overview for clinicians. J Oral Rehabil 2008;35:47694.

8. Attanasio R. Nocturnal bruxism and its clinical management. Dent Clin North Am 1991;35:245-52.

9. The glossary of prosthodontic terms. J Prosthet Dent 2005;94:10-92.

10. Kato T, Dal-Fabbro C, Lavigne GJ. Current knowledge on awake and sleep bruxism: overview. Alpha Omegan 2003;96:24-32.

11. Lavigne GJ, Montplaisir JY. Restless legs syndrome and sleep bruxism: prevalence and association among Canadians. Sleep 1994;17:739-43.

12. Kato T, Thie NM, Montplaisir JY, Lavigne GJ. Bruxism and orofacial movements during sleep. Dent Clin North Am 2001;45:657-84.

13. Manfredini D, Cantini E, Romagnoli M, Bosco M. Prevalence of bruxism in patients with different research diagnostic criteria for temporomandibular disorders (RDC/TMD) diagnoses. Cranio 2003;21:279-85.

14. Carlsson GE, Egermark I, Magnusson T. Predictors of bruxism, other oral parafunctions, and tooth wear over a 20-year follow-up period. J Orofac Pain 2003;17:50-7.
15. Manfredini D, Landi N, Fantoni F, Segù M, Bosco M. Anxiety symptoms in clinically diagnosed bruxers. J Oral Rehabil 2005;32:584-8.

16. Gavish A, Halachmi M, Winocur E, Gazit E. Oral habits and their association with signs and symptoms of temporomandibular disorders in adolescent girls. J Oral Rehabil 2000;27:22-32.

17. Baba K, Haketa T, Clark GT, Ohyama T. Does tooth wear status predict ongoing sleep bruxism in 30-year-old Japanese subjects? Int J Prosthodont 2004;17:39-44.

18. Pergamalian A, Rudy TE, Zaki HS, Greco CM. The association between wear facets, bruxism, and severity of facial pain in patients with temporomandibular disorders. J Prosthet Dent 2003;90:194-200.

19. Torisu T, Wang K, Svensson P, De Laat A, Fujii H, Arendt-Nielsen L. Effect of low-level clenching and subsequent muscle pain on exteroceptive suppression and resting muscle activity in human jaw muscles. Clin Neurophysiol 2007;118:999-1009.

20. Vilmann A, Møller E, Wildschiødtz G. A system for analysis of sleep and nocturnal activity in craniomandibular muscles. J Orofac Pain 1994;8:26677.

21. Clark GT, Rugh JD, Handelman SL. Nocturnal masseter muscle activity and urinary catecholamine levels in bruxers. J Dent Res 1980;59:1571-6.

22. Goulet JP, Clark GT, Flack VF. Reproducibility of examiner performance for muscle and joint palpation in the temporomandibular system following training and calibration. Community Dent Oral Epidemiol 1993;21:72-7.

23. Winocur E, Gavish A, Voikovitch M, Emodi-Perlman A, Eli I. Drugs and bruxism: a critical review. J Orofac Pain 2003;17:99-111.

24. Johansson A, Johansson AK, Omar R, Carlsson GE. Rehabilitation of the worn dentition. J Oral Rehabil 2008;35:548-66.

25. Hedenberg-Magnusson B, Brodda Jansen G, Ernberg M, Kopp S. Effects of isometric contraction on intramuscular level of neuropeptide $\mathrm{Y}$ and local pain perception. Acta Odontol Scand 2006;64:3607.

26. Michalowicz BS, Pihlstrom BL, Hodges JS, Bouchard TJ Jr. No heritability of temporomandibular joint 
signs and symptoms. J Dent Res 2000; 79:1573-8.

27. Johansson A, Johansson AK, Omer R, Carlsson GE. Rehabilitation of the worn dentition. J Oral Rehabil 2008;35:548-66.

28. Addy M, Shellis RP. Interaction between attrition, abrasion and erosion in tooth wear. Monogr Oral Sci 2006;20:17-31.

29. Baba K, Clark GT, Watanabe T, Ohyama T. Bruxism force detection by a piezoelectric film-based recording device in sleeping humans. J Orofac Pain 2003;17:58-64.

30. Dawson PE. Functional occlusion: from TMJ to smile design. $1^{\text {st }}$ ed. St. Louis; Mosby; 2007. p. 334.

31. Haketa T, Baba K, Akishige S, Fueki K, Kino K, Ohyama T. Utility and validity of a new EMGbased bruxism detection system. Int J Prosthodont 2003;16:422-8.

32. Ommerborn MA, Giraki M, Schneider C, Schaefer R, Gotter A, Franz M, Raab WH. A new analyzing method for quantification of abrasion on the Bruxcore device for sleep bruxism diagnosis. J Orofac Pain 2005;19:232-8.

33. Quinn JH. Mandibular exercises to control bruxism and deviation problems. Cranio 1995;13:30-4.
34. van der Zaag J, Lobbezoo F, Wicks DJ, Visscher CM, Hamburger HL, Naeije M. Controlled assessment of the efficacy of occlusal stabilization splints on sleep bruxism. J Orofac Pain 2005;19:151-8.

35. Yap AU. Effects of stabilization appliances on nocturnal parafuctional activities in patients with and without signs of temporomandibular disorders. J Oral Rehabil 1998;25:64-8.

36. Crider A, Glaros AG, Gevirtz RN. Efficacy of biofeedback based treatments for temporo-mandibular disorders. Appl Psychophysiol Biofeedback 2005;30:333-45

37. Takeuchi H, Ikeda T, Clark GT. A piezoelectric film-based intrasplint detection method for bruxism. J Prosthet Dent 2001;86:195-202.

38. Tan EK, Jankovic J. Treating severe bruxism with botulinum toxin. J Am Dent Assoc 2000;131:211-6.

39. Romprè PH, Daigle-Landry D, Guitard F, Montplaisir JY, Lavigne GJ. Identification of a sleep bruxism subgroup with a higher risk of pain. J Dent Res 2007;86:837-42.

40. Chung SC, Kim YK, Kim HS. Prevalence and patterns of nocturnal bruxofacets on stabilization splints in temporomandibular disorder patients. Cranio 2000;18:92-7. 


\section{이갈이 환자의 치과 치료에 관한 임상적 접근을 위한 문헌 고찰}

\section{최유성*}

단국대학교 치과대학 치과보철학교실

이갈이는 치과에서 많이 다루어지는 임상적 주제이다. 이갈이가 생명을 위협하지는 않을 지라도, 마모나 보철물의 파 절, 악안면의 통증과 같은 치과적인 문제를 통해 삶의 질에 영향을 미칠 수 있다. 본 고찰에서는 이갈이에 대한 진단법 을 알아보고 임상적 상황에서 가능한 다양한 치료 방법에 관한 정보를 알아봄으로써, 그 방법들의 효과와 유용성에 대 해 정리해보고자 하였다. 기술적으로 효용성이 있고 치료 결정에 영향을 미치는 확실한 이갈이 진단법이나 치료법은 아직 없기 때문에 치료의 일차적인 목표는 이갈이로 인한 구강 악안면 조직의 손상을 막고 통증이나 관련 증상을 치료 하는 데 있다고 본다. 따라서 행동수정요법이나 구강 장치요법, 물리 요법 같은 가역적인 방법들을 복합적으로 사용하 는 것이 추천된다.

(구강회복응용과학지 2014;30(1):36-44)

주요어: 이갈이; 이악물기; 임상적 접근; 진단; 치료 